\title{
Morphologic and transcriptomic assessment of bovine embryos exposed to dietary long-chain fatty acids
}

\author{
Reza Salehi ${ }^{1,3}$, Marcos G Colazo ${ }^{2}$, Stephen Tsoi ${ }^{1}$, Amir Behrouzi ${ }^{1}$, Benjamin K Tsang ${ }^{3,4}$, \\ Michael K Dyck ${ }^{1}$, Masahito Oba ${ }^{1}$ and Divakar J Ambrose ${ }^{1,2}$ \\ ${ }^{1}$ Department of Agricultural, Food and Nutritional Science, University of Alberta, Edmonton, Alberta, Canada, \\ ${ }^{2}$ Livestock Research Branch, Alberta Agriculture and Forestry, Edmonton, Alberta, Canada, ${ }^{3}$ Departments of \\ Obstetrics and Gynecology \& Cellular and Molecular Medicine, Interdisciplinary School of Health Sciences, \\ University of Ottawa, and Chronic Disease Program, Ottawa Hospital Research Institute, Ottawa, Ontario, Canada \\ and ${ }^{4}$ Macau Institute for Applied Research in Medicine and Health, State Key Laboratory of Quality Research in \\ Chinese Medicine, Macau University of Science and Technology, Macau, China
}

Correspondence should be addressed to D J Ambrose; Email: divakar.ambrose@gov.ab.ca

\begin{abstract}
The main objectives of this study were to determine the influence of diets enriched in $\alpha$-linolenic, linoleic or oleic acid on the development and transcriptomic profile of embryos collected from dairy cattle. Non-lactating Holstein cows received one of the three diets supplemented with $8 \%$ rolled oilseeds: flax (FLX, $n=8)$, sunflower (SUN, $n=7)$ or canola $(C A N, n=8)$. After a minimum 35-day diet adaptation, cows were superovulated, artificially inseminated and ova/embryos recovered non-surgically after 7.5 days. Cows fed FLX had less degenerated embryos and more viable embryos than those fed CAN or SUN. In total, 175 genes were differentially expressed in blastocysts from cows fed FLX than in cows fed CAN or SUN. These differentially expressed genes were mainly involved in cellular growth and proliferation, cellular development, and cell survival and viability. In conclusion, dietary n-3 polyunsaturated fatty acids reduced early embryonic degeneration possibly through improving embryonic cell survival and viability. Reproduction (2016) 152 715-726
\end{abstract}

\section{Introduction}

The establishment of pregnancy in cattle requires ovulation of a competent oocyte, insemination at the optimum time and production of sufficient embryonic interferon $\tau$ to inhibit prostaglandin $\mathrm{F}_{2} \alpha \quad\left(\mathrm{PGF}_{2} \alpha\right)$ release (Hunter 1989, Robinson et al. 2006). In this regard, it has been shown that feeding dairy cows diets supplemented with n-3 polyunsaturated fatty acids such as eicosapentaenoic and docosahexaenoic acids suppressed $\mathrm{PGF}_{2} \alpha$ production, delayed luteal regression and improved conception rate (Burke et al. 1997). Although it is widely accepted that dietary fats (Thatcher 2010) and fatty acids (Mattos et al. 2000) enhance reproductive performance in dairy cows, the effect of fatty acids on the transcriptomic profile of early embryos remains unknown.

Bovine oocytes contain $63 \mu \mathrm{g}$ fat (McEvoy et al. 2000) that is used as an energy source during oocyte maturation and the extended period of embryo development before implantation (Paczkowski et al. 2013, 2014). Inhibition of fatty acid oxidation in bovine oocytes reduced their capacity to form blastocysts after fertilization (Ferguson \& Leese 2006). High concentrations of non-esterified fatty acids (NEFA) and ketone bodies were found in the follicular fluid of the dominant follicle (Leroy et al. 2004) during early postpartum period. In vitro culture models indicated that high-NEFA concentrations were detrimental to the oocyte's nuclear maturation, developmental competence, granulosa cell viability and steroidogenic capacity (Leroy et al. 2005, Vanholder et al. 2005). It has been demonstrated that palmitic and stearic acids predominate the follicular fluid of lactating dairy cows and adding these fatty acids to in vitro maturation medium of bovine cumulus-oocyte complexes (COC) inhibited cumulus expansion and reduced progression to metaphase II and blastocyst rate (Leroy et al. 2005). However, adding oleic acid to in vitro maturation medium reversed the detrimental effects of palmitic and stearic acids on subsequent embryo development (Aardema et al. 2011). Canola seed has high amount of oleic acid (61\% of total fat) and is a common ingredient in dairy cattle rations in Western Canada; however, its influence on in vivo early embryonic development has not been investigated.

Previously, our group (Thangavelu et al. 2007) found that feeding lactating dairy cows a diet enriched 
in $\alpha$-linolenic (flaxseed) or linoleic acid (sunflower seed) enhanced embryonic development through a significant increase in blastomere number compared with feeding a diet enriched in saturated fatty acid (high in stearic and palmitic acids). Moreover, cows that were fed a diet supplemented with a partially rumen protected $n-3$ polyunsaturated fatty acids (PUFA; high in eicosapentaenoic and docosahexaenoic acids) had a lower proportion of degenerated embryos than those fed a diet supplemented with palmitic acid (Childs et al. 2008). A combination of in vivo and in vitro approaches has been used to examine the effect of PUFA on oocyte developmental competence (Moallem et al. 2013). In this regard, feeding a diet enriched in $\alpha$-linolenic acid (flaxseed oil) increased the number of follicles and oocytes collected by transvaginal ultrasonography, enhanced the cleavage rate of in vitro fertilized oocytes and tended to improve blastocyst rate compared with feeding a diet enriched in saturated fatty acid (Moallem et al. 2013). In another study, adding $\alpha$-linolenic acid to in vitro maturation medium enhanced oocyte maturation and subsequent embryo development, whereas adding linoleic acid significantly inhibited cumulus cell expansion, delayed development of the oocytes to the metaphase II stage and reduced cleavage and blastocyst rates (Marei et al. 2009, 2010). These results suggest that $\alpha$-linolenic acid enhanced embryo development most probably through improved oocyte competence. Although these studies have provided significant information regarding the effect of fatty acids on in vivo embryo development or on oocyte competence, very limited information is available about the transcriptomic profile of embryos exposed to different fatty acids during their development. Therefore, the main objectives of this study were to examine the influence of diets enriched in $\alpha$-linolenic, linoleic or oleic acid on the development and transcriptomic profile of embryos collected from dairy cattle.

\section{Materials and methods}

\section{Embryo production}

The study was conducted at the Laird W McElroy Environmental \& Metabolism Research Centre, University of Alberta, Edmonton, Canada, with all animal experimental procedures approved (Protocol \# AUP00000131) by the University of Alberta Animal Care and Use Committee and animals were cared in accordance with the Guidelines of the Canadian Council of Animal Care (1993). Non-lactating Holstein cows $(726 \pm 11.4 \mathrm{~kg})$ were blocked by parity and body weight and were assigned to one of the three diets supplemented with flax (FLX; high in $\alpha$-linolenic acid, $n=8$ ), sunflower (SUN; high in linoleic acid, $n=7$ ) or canola (CAN; high in oleic acid, $n=8$ ) oilseed. Cows were individually fed a diet containing hay $(8.8 \mathrm{~kg} /$ day on a dry matter basis) and concentrate mix (3.8 kg/day on a dry matter basis). The concentrate portion of the diet contained $0.99 \mathrm{~kg} /$ day dry matter basis of rolled canola seed, sunflower seed or flaxseed. The energy and protein content of dietary treatments and fatty acid profiles of supplemented oilseeds are presented in Table 1. After a minimum 35-day diet adaptation, ovarian status was synchronized and superstimulated as described previously (Colazo et al. 2005) with purified porcine folliclestimulating hormone (Folltropin- $\mathrm{V}$; Bioniche Animal Health Inc, Belleville, ON, Canada). Cows were then artificially inseminated twice, $12 \mathrm{~h}$ apart, with frozen-thawed semen from the same sire and ova/embryos recovered nonsurgically 7.5 days post-insemination. A total of 35 embryo collections (uterine flushing) were performed (FLX: 12, SUN: 11 and CAN: 12). Once started on a diet, cows continued to receive the same diet until the end of the experiment. Before embryo collection, ovarian status was determined by transrectal ultrasonography and cows with less than two corpora lutea were not used for embryo collection. Collected embryos were classified according to the Manual of the International Embryo Transfer Society (3rd ed, Savoy, IL, USA) as Stage 1 (unfertilized), Stage 2 (2-8 cells), Stage 3 (early morula), Stage 4 (morula), Stage 5 (early blastocyst), Stage 6 (blastocyst) and Stage 7 (expanding or expanded blastocyst). In this study, embryos of Stages 6 and 7 were considered blastocysts. We defined transferable embryos

Table 1 Energy and protein content of dietary treatments and fatty acid profile of supplemented oilseeds.

\begin{tabular}{|c|c|c|c|}
\hline & \multicolumn{3}{|c|}{ Dietary treatments } \\
\hline & Flaxseed & Sunflower seed & Canola seed \\
\hline NEL (Mcal/kg) & 1.43 & 1.48 & 1.55 \\
\hline Crude protein $(\%)$ & 16.90 & 17.20 & 16.60 \\
\hline \multicolumn{4}{|c|}{ Fatty acid profile of oilseeds (g/100 g of total fatty acids) } \\
\hline Palmitic acid (SFA) & 5.41 & 6.80 & 4.08 \\
\hline Stearic acid (SFA) & 3.72 & 5.29 & 1.80 \\
\hline Oleic acid (MUFA) & 18.04 & 12.47 & 61.18 \\
\hline Linoleic acid (PUFA) & 15.37 & 73.13 & 18.84 \\
\hline$\alpha$-linolenic acid (PUFA) & 56.52 & 0.71 & 9.62 \\
\hline$n-6: n-3$ ratio & 0.27 & 10.3 & 1.95 \\
\hline Total SFA & 9.57 & 13.55 & 7.175 \\
\hline Total MUFA & 18.11 & 12.63 & 63.79 \\
\hline Total PUFA & 71.91 & 73.84 & 28.50 \\
\hline PUFA:SFA ratio & 7.51 & 5.45 & 3.97 \\
\hline
\end{tabular}

MUFA, monounsaturated fatty acids; PUFA, polyunsaturated fatty acids; SFA, saturated fatty acids. 
and the proportion of viable embryos as total number of grade 1 and 2 blastocysts and the proportion of grade 1 and 2 blastocysts over total collected embryos respectively. Grade 1 and 2 blastocysts from each cow were pooled to create two or more biological replicates per cow with each pool consisting of one to five blastocysts.

\section{Total RNA isolation for microarray analysis}

We extracted total RNA from four biological replicates per dietary treatment. Total RNA was extracted using Arcturus PicoPure RNA Isolation Kit (Applied Biosystems) in both the experiments (microarray and real-time q-PCR). Total RNA quality and integrity of each sample were evaluated by Bioanalyzer RNA 6000 Pico LabChip (Agilent Technologies), and all samples showed RNA integrity number greater than 7.5 in both the experiments.

\section{RNA amplification and labelling for microarray analysis}

The extracted RNA was amplified using RiboAmp HSPlus kit (Applied Biosystems) as per the manufacturer's instructions and generated amplified RNA (aRNA) targets for microarray reactions. Thereafter, the quantity and quality of the aRNA products from RNA amplification reactions were evaluated by spectrophotometry (ND-2000, Nanodrop Technologies, Wilmington, DE, USA) and microelectrophoresis (2200 TapeStation, Agilent Technologies) respectively. aRNA weighing $2 \mu \mathrm{g}$ was used in each labelling reaction. All labelling reactions were performed using the ULS Fluorescent Labelling Kit (Kreatech Diagnostics, Amsterdam, The Netherlands) as per the manufacturer's instructions. The labelling of aRNA targets was processed under an ozone-free environment. The labelling efficiency of each labelled sample was evaluated using spectrophotometry (ND-2000, Nanodrop Technologies, Wilmington, DE, USA).

\section{Microarray experimental procedure}

The amplified RNA (825 ng per replicate) was hybridized on Agilent-manufactured EmbryoGENE slides in a two-colour dye swap design (Robert et al. 2011). After $17 \mathrm{~h}$ at $65^{\circ} \mathrm{C}$, the microarray slides were washed in Gene Expression Wash Buffer 1 (room temperature; $1 \mathrm{~min}$ ), in Gene Expression Wash Buffer $2\left(42^{\circ} \mathrm{C}, 3 \mathrm{~min}\right)$, in $100 \%$ acetonitrile (room temperature, $10 \mathrm{~s})$, and in Stabilization and Drying Solution (30s; Agilent Technologies) and scanned with Axon 4200AL scanner (Molecular Device, Sunnyvale, CA, USA). Intensity files were analyzed with FlexArray (Blazejczyk et al. 2007).

Intensity raw data were corrected by background subtraction and normalized within (green or red) and between each array (Loess and quartile respectively) (Tsoi et al. 2012). The dataset of the microarray results has been deposited in NCBI's Gene Expression Omnibus and is accessible through Gene Expression Omnibus series accession number GSE67686.

To identify differentially expressed genes, the normalized microarray data were analyzed using the 'limma' package (Smyth 2005) of Bio-conductor through FlexArray (Robert et al. 2011).
For any particular analysis, a $2 \times 2$ comparison was performed (FLX vs CAN; SUN vs CAN; and FLX vs SUN), and only genes with $P$ value $\leq 0.05$ and a fold-change $(\mathrm{FC}) \geq 2.0$ were considered significantly upregulated or downregulated.

\section{Functional analysis of differential gene expression profile}

The expression data obtained from the comparative transcriptomic analysis were analyzed using the Ingenuity Pathway Analysis (IPA; Ingenuity Systems, www.ingenuity.com).

\section{Biological function analysis}

The biological functions were performed under BH-FDR multiple testing correction conditions. Only the biological functions with a $\mathrm{BH}-\mathrm{FDR}$-corrected $P$ value $(\mathrm{B}-\mathrm{H} P$ value $)$ $<0.05$ and with a $-\log (\mathrm{B}-\mathrm{H} P$ value $)>2.0$ were considered significant.

\section{Network generation}

Differentially expressed genes ( $P$ value $\leq 0.05$ and a foldchange $(F C) \geq 2.0$ ) called network-eligible molecules, were overlaid onto a global molecular network developed from the information contained in Ingenuity's Knowledge Base.

\section{IPA upstream regulator analysis}

The upstream regulator analysis predicted the activation status of the upstream regulators by calculating a regulation Z-score and an overlap $P$ value, which were based on the number of known regulation target genes from the dataset of interest, expression changes of these target genes, and their agreement with the literature findings. Upstream regulators with an overlap $P$ value $\leq 0.05$ and an IPA activation $Z$-score $\geq 2.0$ (or $\leq-2.0$ ) were considered significantly activated (or inhibited).

IPA regulation $Z$-score and overlap $P$ value were calculated as described in IPA white papers 'A Novel Approach to Predicting Upstream Regulators' and a full description is available on the IPA website (http://www.ingenuity.com) under 'Upstream Regulator Analysis', 'Biological Functions Analysis' and 'Ingenuity Canonical Pathways Analysis'.

\section{Validation of microarray results}

For validation, total RNA was extracted from another three biological replicates per dietary treatment (each with a pool of three to five grade 1 and 2 blastocysts). The extracted RNA was used to confirm the expression of six genes (PTGS2, LGALS3, ANXA1, IL1RN, KRT19 and SRXN1) based on the microarray data analysis by real-time quantitative PCR (q-PCR).

\section{Real-time $q$-PCR}

Primers were designed (Supplementary Table 1, see section on supplementary data given at the end of this article) using Integrated DNA Technologies (https://www.idtdna.com/ scitools/Applications/RealTimePCR) and analyzed by BLAST 
(http://blast.ncbi.nlm.nih.gov/Blast.cgi) to verify primer specificity. A total of $1 \mathrm{ng}$ of total RNA extracted from each pool of embryos was reverse transcribed into cDNA using a high-capacity reverse transcriptase (SuperScript VILO cDNA Synthesis Kit, Invitrogen) in a $20 \mu \mathrm{L}$ reverse transcription (RT) reaction volume, as per the manufacturer's instructions. The cDNA products were then diluted once, and $1 \mu \mathrm{L}$ of the diluted cDNA was used as the template with the StepOnePlus RealTime PCR System (Applied Biosystems) and Fast SYBR Green Master Mix (Applied Biosystems). Melting curve analyses were performed at the end of each run to ensure the specificity of the amplification. Each assay included negative controls with no template, and each sample was analyzed in duplicate. Primer efficiency was determined using the standard curve method (with at least five serial dilutions) in a pool of all samples.

The mRNA abundance of target genes was normalized to the expression level of a reference gene (ribosomal protein L19 (RPL19)), according to the comparative Ct method ( $\triangle \Delta \mathrm{Ct})$ with correction for amplification efficiency of each primer pair (Pfaffl 2001, Abedini et al. 2015).

\section{Serum metabolites and fatty acid composition}

To evaluate the effect of dietary treatments on serum fatty acid profiles and metabolites (NEFA, BHBA and glucose), blood samples were collected in non-heparinized, silicone-coated tubes (Vacutainer, Becton Dickinson, Franklin Lakes, NJ, USA) at oestrus and kept $4 \mathrm{~h}$ at room temperature for clotting. Blood samples were then centrifuged $\left(3000 \mathrm{~g}, 20 \mathrm{~min}, 4^{\circ} \mathrm{C}\right)$ and serum harvested. Serum NEFA (NEFA-C kit; Wako), $\beta$-hydroxybutyric acid (BHBA; Roche Diagnostics) and glucose (P7119; SigmaAldrich) were determined using commercially available kits in triplicate. The intra- and inter-assay coefficients of variation for NEFA, BHBA and glucose were 1.49 and 3.32, 2.51 and 6.71, and 1.38 and $2.42 \%$ respectively. The minimum sensitivity of the kits used for NEFA, BHBA and glucose were $62.5 \mathrm{mEq} / \mathrm{dL}$,
$2.5 \mathrm{mg} / \mathrm{dL}$ and $6.25 \mathrm{mg} / \mathrm{dL}$ respectively. Fatty acids in serum samples were extracted (Folch et al. 1957) and fatty acid composition was assessed by gas chromatography (CruzHernandez et al. 2007).

\section{Statistical analysis}

The abundance of mRNA, serum metabolites and fatty acid profile as well as the total number of corpora lutea, anovulated follicles, embryos, blastocysts, unfertilized ova and degenerated embryos were analyzed using the MIXED procedure of SAS (version 9.3, 2011; SAS Institute, Cary, NC, USA). The statistical model included dietary treatment as the main effects. Moreover, fertilization rate and proportion of viable embryos were analyzed using the GENMOD procedure of SAS. The statistical model included dietary treatment as main effect. Model specifications included a binomial distribution and logit link function. The results are expressed as proportion or as mean \pm S.E.M. For all results, $P \leq 0.05$ were considered significant, whereas $P>0.05$ but $<0.10$ was considered trends.

\section{Results and discussion}

The evaluation of serum fatty acid profiles indicated that the main differences were found between serum fatty acid profiles of cows fed FLX (high in $\alpha$-linolenic acid) and SUN (high in linoleic acid) (Table 2). Moreover, the concentration of serum metabolites (NEFA, BHBA and glucose) did not differ between dietary groups (Table 2), indicating that cows were in similar metabolic states. Superovulatory response did not differ among dietary treatments based on the number of $\mathrm{CL}$, anovulated follicles and total ova/embryos collected (Table 3). Cows fed SUN tended $(P=0.06)$ to produce more transferable embryos (total number of grade 1 and 2 embryos) than

Table 2 The concentrations of metabolites and fatty acid profile of serum collected from cows fed diets supplemented with flax (FLX), sunflower (SUN) or canola (CAN) oilseed.

\begin{tabular}{|c|c|c|c|}
\hline & \multicolumn{2}{|c|}{ Treatments } & \multirow[b]{2}{*}{$\mathrm{CAN}^{\S}$} \\
\hline & FLX* & $\mathrm{SUN}^{\ddagger}$ & \\
\hline NEFA $(\mathrm{mEq} / \mathrm{dL})$ & $125.62 \pm 14.82$ & $91.81 \pm 14.82$ & $134.02 \pm 14.82$ \\
\hline $\mathrm{BHBA}(\mathrm{mg} / \mathrm{dL})$ & $11.00 \pm 1.19$ & $9.23 \pm 1.19$ & $11.17 \pm 1.19$ \\
\hline Glucose (mg/dL) & $61.27 \pm 1.96$ & $63.02 \pm 1.96$ & $58.89 \pm 1.96$ \\
\hline \multicolumn{4}{|c|}{ Fatty acid profile of serum (g/100g of total fatty acids) } \\
\hline Palmitic acid (SFA) & $11.86 \pm 0.71$ & $11.76 \pm 0.71$ & $12.76 \pm 0.71$ \\
\hline Stearic acid (SFA) & $22.88 \pm 1.04$ & $22.19 \pm 1.04$ & $21.89 \pm 1.04$ \\
\hline Oleic acid (MUFA) & $9.85 \pm 1.20$ & $9.79 \pm 1.07$ & $10.33 \pm 1.20$ \\
\hline Linoleic acid (PUFA) & $32.13 \pm 3.06^{\mathrm{a}, \mathrm{c}}$ & $41.63 \pm 2.74^{\mathrm{b}}$ & $41.05 \pm 3.06^{\mathrm{a}, \mathrm{b}, \mathrm{d}}$ \\
\hline$\alpha$-linolenic acid (PUFA) & $17.69 \pm 2.09^{a}$ & $6.08 \pm 1.87^{b}$ & $10.55 \pm 2.09^{\mathrm{b}}$ \\
\hline Total n- 6 fatty acids & $33.17 \pm 2.97^{\mathrm{a}}$ & $44.14 \pm 2.66^{b}$ & $42.67 \pm 2.97^{b}$ \\
\hline Total n-3 fatty acids & $20.37 \pm 2.24^{\mathrm{a}}$ & $10.89 \pm 2.00^{\mathrm{b}}$ & $11.79 \pm 2.24^{b}$ \\
\hline$n-6: n-3$ ratio & $1.65 \pm 1.19^{a}$ & $5.35 \pm 1.06^{\mathrm{b}}$ & $4.02 \pm 1.19^{\mathrm{a}, \mathrm{b}}$ \\
\hline Total SFA & $34.87 \pm 1.34$ & $34.69 \pm 1.20$ & $34.90 \pm 1.34$ \\
\hline Total MUFA & $11.46 \pm 2.06$ & $9.79 \pm 1.84$ & $13.62 \pm 2.06$ \\
\hline Total PUFA & $53.55 \pm 2.65$ & $55.03 \pm 2.37$ & $54.76 \pm 2.65$ \\
\hline PUFA:SFA ratio & $0.86 \pm 0.22$ & $0.85 \pm 0.19$ & $0.81 \pm 0.22$ \\
\hline
\end{tabular}

Within a row, values with no common superscripts differ ${ }^{\mathrm{a}, \mathrm{b}} P$ value $\leq 0.05 ; \mathrm{c}, \mathrm{d} P$ value $<0.10$.

*Serum collected from cows fed a diet supplemented with flaxseed; ${ }^{*}$ Serum collected from cows fed a diet supplemented with sunflower seed; §Serum collected from cows fed a diet supplemented with canola seed.

BHBA, $\beta$-hydroxybutyric acid; MUFA, monounsaturated fatty acids; NEFA, non-esterified fatty acid; PUFA, polyunsaturated fatty acids; SFA, saturated fatty acids. 
Table 3 Superovulatory response and embryo production* in cows fed diets supplemented with flax (FLX), sunflower (SUN) or canola (CAN) seed.

\begin{tabular}{|c|c|c|c|}
\hline & \multicolumn{3}{|c|}{ Dietary treatment } \\
\hline & FLX & SUN & CAN \\
\hline Corpora lutea $(n)$ & $13.1 \pm 1.5$ & $14.5 \pm 1.2$ & $12.8 \pm 2.6$ \\
\hline Anovulated follicles $(n)$ & $2.6 \pm 0.9$ & $2.0 \pm 1.1$ & $3.0 \pm 1.4$ \\
\hline Total ova/embryos $(n)$ & $7.3 \pm 1.2$ & $8.6 \pm 1.7$ & $7.5 \pm 2.0$ \\
\hline Transferable embryo $(n)$ & $4.8 \pm 1.3^{c, d}$ & $6.1 \pm 1.7^{c}$ & $4.3 \pm 1.5^{d}$ \\
\hline Unfertilized $(n)$ & $1.8 \pm 0.9^{b}$ & $0.6 \pm 0.5^{\mathrm{a}}$ & $1.3 \pm 0.6^{b}$ \\
\hline Degenerated $(n)$ & $0.7 \pm 0.4^{\mathrm{a}}$ & $1.9 \pm 0.5^{\mathrm{b}}$ & $1.9 \pm 0.6^{b}$ \\
\hline Fertilization rate (\%) & $75.3^{\mathrm{b}}$ & $93.0^{\mathrm{a}}$ & $82.7^{b}$ \\
\hline Proportion of viable embryos (\%) & $87.3^{\mathrm{a}, \mathrm{c}}$ & $76.3^{a, b, d}$ & $69.4^{\mathrm{b}}$ \\
\hline
\end{tabular}

Within a row, values with no common superscripts differ ${ }^{a, b} p$ value $\leq 0.05 ; c, d p$ value $<0.10$.

*Embryos were harvested from a total of 35 embryo collections (FLX, $n=12$; SUN, $n=11$; and CAN, $n=12$ ).

those fed CAN, but it did not differ from those fed FLX. Cows fed SUN had fewer unfertilized ova and, hence, greater fertilization rate than those fed either CAN or FLX. Previous findings indicated that a diet enriched in linoleic acid had either a positive (Cerri et al. 2009) or no (Thangavelu et al. 2007) effect on the fertilization rate in lactating dairy cows. Conversely, using an in vitro model, it has been demonstrated that linoleic acid negatively influences oocyte maturation and subsequent blastocyst development (Marei et al. 2010), a response attenuated by adding antioxidants during the in vitro maturation (Khalil et al. 2013). Although these contradictory results could be associated with the status of animals (lactating vs non-lactating) or the model used (in vitro vs in vivo), the effect of linoleic acid on bovine oocyte competence and fertilization rate remains controversial.

Cows fed FLX had fewer degenerated embryos than those fed either CAN or SUN (Table 3). Feeding FLX also increased $(P<0.05)$ or tended to increase $(P<0.10)$ the proportion of viable embryos (the proportion of grade 1 and 2 embryos over total collected embryos) compared with feeding CAN or SUN respectively. Similarly, cows fed a diet supplemented with a partially rumen protected n-3 PUFA (high in eicosapentaenoic and docosahexaenoic acids) had a lower proportion of degenerated embryos compared with those fed a diet supplemented with palmitic acid (Childs et al. 2008). It has also been reported that feeding cows a diet enriched in $\alpha$-linolenic acid (flaxseed oil) increased the presence of $\alpha$-linolenic acid in collected oocytes and subsequently those oocytes had greater cleavage rate and tended to have higher blastocyst rate compared with those collected from cows fed a diet enriched in saturated fatty acid (Moallem et al. 2013). Therefore, it is plausible that the reduced number of degenerated embryos in cows fed FLX resulted from enhanced embryo development.

Evaluation of the transcriptomic profile revealed that 175 genes were differentially expressed in blastocysts from cows fed FLX compared with those from cows fed SUN (Fig. 1; FC $>2.0$ and $P$ value $<0.05$; full list of genes provided in Supplementary Table 2). However, when FLX vs CAN and SUN vs CAN were compared, only four and 14 differentially expressed genes, respectively, were evident (Fig. 1). Given that the serum fatty acid profile of CAN and SUN groups were mostly similar, the absence of a greater difference in gene expression between embryos of these two diets is not surprising. However, the lack of difference in gene expression between CAN and FLX groups is somewhat intriguing, although it may

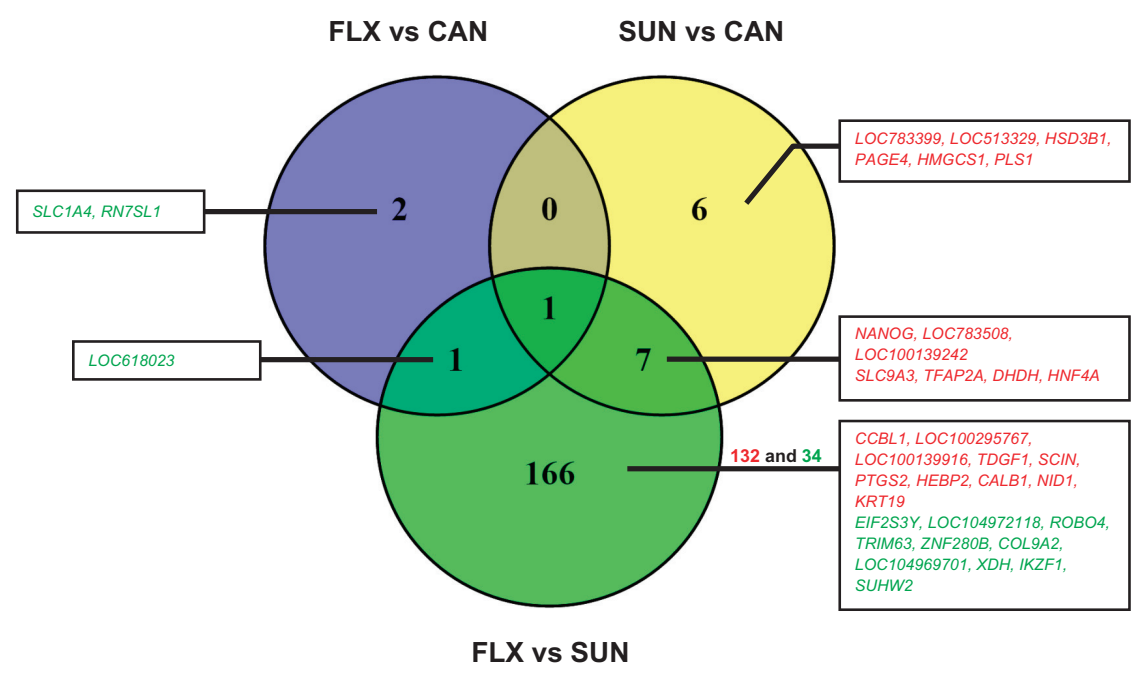

Figure 1 Number of differentially expressed genes $(\geq 2.0$-fold changes with a $P$ value $\leq 0.05$ ) in embryos (Day 7.5) collected from cows fed a diet supplemented with flax (FLX), sunflower (SUN) or canola (CAN) oilseed. The 175 differentially expressed genes were used for further functional analysis with Ingenuity Pathway Analysis. Gene names appearing in red and green colour indicate up- and down-regulated genes respectively. 
be partially explained by the differences in $n-6: n-3$ ratio among FLX, SUN and CAN groups. Although the $\mathrm{n}-6: \mathrm{n}-3$ ratio was significantly lower in FLX compared with SUN, it neither differed between FLX and CAN or between SUN and CAN, leading to the speculation that $n-6: n-3$ ratio in maternal diets could influence embryonic gene expression.

As most of the differences were between FLX and SUN (175 differentially expressed genes), further functional analysis of IPA was performed on only this comparison. The list of biological functions influenced (BH-FDR-corrected $P$ value (B-H $P$ value) $<0.05$ with a $-\log (\mathrm{B}-\mathrm{H} P$ value $)>2.0$ ) by FLX vs SUN, which includes cellular growth and proliferation, cellular development, lipid metabolism and molecular transport, is presented in Table 4. Moreover, cell viability and survival functions were activated functions having Z-score $>2.0$ (Fig. 2). IPA analysis also identified 13 activated pathways based on differentially expressed genes (Supplementary Table 3).

Blastocysts collected from cows fed FLX had greater mRNA expression of claudin 4 (CLDN4, 2.4-fold) and solute carrier family 9 , subfamily A, member 3 (SLC9A3, 7.0-fold) compared with those collected from cows fed
SUN. It has been reported that Cldn4 and Cldn6 are essential for tight junctions and blastocyst development (Moriwaki et al. 2007). In this regard, when embryos were cultured with an inhibitor of Cldn4 and Cldn6, the development of normal blastocysts was remarkably reduced (Moriwaki et al. 2007). The solute carrier family 9 (SLC9A) (previously known $\mathrm{Na}^{+} / \mathrm{H}^{+}$exchangers (NHEs)) consists of five members (SLC9A1, 2, 3, 4 and $5)$, which are located in the plasma membrane and involved in intracellular $\mathrm{pH}$ maintenance, cell volume regulation and transduction of signals that promote cell proliferation (Yun et al. 1995). It was found that the addition of specific SLC9A3 inhibitor to embryo cultures did not affect the embryonic development from twocell stage to morula stage but inhibited the formation of blastocyst in a concentration-dependent manner (Kawagishi et al. 2004).

Our results also indicated that blastocysts collected from cows fed FLX had higher mRNA expression of keratin 19 (KRT19, 8.8-fold), lectin galactoside-binding soluble 3 (LGALS3, 2.1-fold) and annexin A1 (ANXA1, 2.5 -fold) compared with those collected from cows fed SUN. A previous study has shown that Krt19 is essential for the integrity of trophoblast cells and embryo survival

Table 4 List of biological functions based on differentially expressed genes in Day 7.5 embryos collected from cows fed diets supplemented with flaxseed (FLX) vs sunflower seed (SUN).

\begin{tabular}{|c|c|c|}
\hline Category & B-H $P$ value & Genes \\
\hline Cellular growth and proliferation & 2.33E-03-3.65E-02 & $\begin{array}{l}\text { B2M, ID2, LGALS3, GADD45B, EMILIN2, XDH, HMGN1, NR3C1, XRCC2, } \\
\text { CLDN4, TIMP1, ANXA1, CXCL14, IFI3O, MGLL, IKZF1, ABCG2, ULBP1, } \\
\text { TDGF1, PLCL2, EFNA1, FOS, IL1RN, KRT19, BTG2, ZAP70, EDN3, } \\
\text { PTGS2, GLDC, SFN }\end{array}$ \\
\hline Cellular development & $2.33 \mathrm{E}-03-3.65 \mathrm{E}-02$ & $\begin{array}{l}\text { B2M, ID2, GADD45B, LGALS3, XDH, HMGN1, CD8B, NR3C1, CLDN4, } \\
\text { TIMP1, ANXA1, CXCL14, GIMAP4, PLAC8, TBX3, IKZF1, ABCG2, } \\
\text { ULBP1, TDGF1, SCIN, PLCL2, EFNA1, UBD, FOS, IL1RN, ZAP70, BTG2, } \\
\text { EDN3, PTGS2, SFN, GLDC }\end{array}$ \\
\hline Lipid metabolism & $3.45 \mathrm{E}-03-3.65 \mathrm{E}-02$ & $\begin{array}{l}\text { SCIMP, LIPH, LTA4H, LGALS3, XDH, ABCG2, HMGN1, PLA2R1, SLC34A2, } \\
\text { NR3C1, FOS, MGAT4A, MGST2, IL1RN, TIMP1, ANXA1, CXCL14, } \\
\text { MGLL, EDN3, PTGS2 }\end{array}$ \\
\hline Molecular transport & $3.45 \mathrm{E}-03-3.65 \mathrm{E}-02$ & $\begin{array}{l}\text { SCIMP, LTA4H, LGALS3, XDH, ABCG2, HMGN1, PLA2R1, SLC34A2, } \\
\text { NR3C1, GSTO1, FOS, SLC23A1, MGAT4A, IL1RN, TIMP1, ANXA1, } \\
\text { CXCL14, MGLL, EDN3, PTGS2 }\end{array}$ \\
\hline Small molecule biochemistry & $3.45 \mathrm{E}-03-3.65 \mathrm{E}-02$ & $\begin{array}{l}\text { SCIMP, LTA4H, DPYS, LGALS3, XDH, PLA2R1, HMGN1, HSD17B11, PFKL, } \\
\text { NR3C1, GFPT2, SLC23A1, TIMP1, ANXA1, CXCL14, MGLL, LIPH, } \\
\text { ABCG2, SLC34A2, GSTO1, FOS, MGAT4A, MGST2, IL1RN, GCSH, } \\
\text { PTGS2, EDN3, GLDC }\end{array}$ \\
\hline Amino acid metabolism & 3.88E-03-3.02E-02 & GCSH, GLDC \\
\hline Post-translational modification & 3.88E-03-3.16E-02 & GCSH, BTG2, AS3MT, GLDC \\
\hline Cell death and survival & $4.82 \mathrm{E}-03-3.65 \mathrm{E}-02$ & $\begin{array}{l}\text { B2M, ID2, EMILIN2, GADD45B, LGALS3, XDH, HMGN1, AS3MT, PTPN5, } \\
\text { CAMK2N2, NR3C1, SCARB2, XRCC2, CLDN4, TIMP1, PRSS8, ANXA1, } \\
\text { ZNF28OB, MAP1LC3A, CALB1, GIMAP4, HEBP2, PLAC8, CCBL1, TBX3, } \\
\text { IKZF1, ABCG2, ULBP1, TDGF1, ANXA4, SCIN, SRXN1, EFNA1, UBD, } \\
\text { FOS, IL1RN, KRT19, ZAP70, BTG2, PTGS2, SFN }\end{array}$ \\
\hline Cell cycle & $5.76 \mathrm{E}-03-3.65 \mathrm{E}-02$ & $\begin{array}{l}\text { ID2, GADD45B, LGALS3, TBX3, ABCG2, IKZF1, HMGN1, ORC6, } \\
\text { CAMK2N2, NR3C1, UBD, XRCC2, FOS, TACC2, TIMP1, KRT19, ZAP70, } \\
\text { BTG2, EDN3, PTGS2, SFN, PLAC8 }\end{array}$ \\
\hline Nucleic acid metabolism & 6.03E-03-3.65E-02 & $D P Y S, X D H, A B C G 2, G L D C$ \\
\hline Cellular assembly and organization & $9 \mathrm{E}-03-3.65 \mathrm{E}-02$ & UBD, LGALS3, CLDN4, IKZF1, KRT19, XDH, HMGN1, SFN, NR3C1 \\
\hline Cellular function and maintenance & $9 \mathrm{E}-03-3.65 \mathrm{E}-02$ & $\begin{array}{l}\text { B2M, ID2, LGALS3, GADD45B, XDH, HMGN1, CD8B, NR3C1, CLDN4, } \\
\text { ANXA1, IFI30, MAP1LC3A, CALB1, DSC2, GIMAP4, PLAC8, IKZF1, } \\
\text { ABCG2, SLC34A2, PLCL2, SRXN1, EFNA1, UBD, FOS, IL1RN, ZAP70, } \\
\text { EDN3, PTGS2 }\end{array}$ \\
\hline DNA replication, recombination and repair & $9 \mathrm{E}-03-3.65 \mathrm{E}-02$ & $U B D, X R C C 2, I K Z F 1, S F N, G L D C, N R 3 C 1$ \\
\hline
\end{tabular}


in mice (Hesse et al. 2000). Several studies have also reported that LGALS3 is involved in cell proliferation, growth, adhesion and polarization (Liu et al. 2002, Friedrichs et al. 2007, Nangia-Makker et al. 2007) and, more importantly, in cell cycle progression and cell survival (Liu et al. 2002). Furthermore, it was 2.8 times more abundant at blastocyst stage compared with morula stage in bovine (Demant 2012), suggesting that LGALS3 is important for blastocyst development. It has been reported that all annexin family members participate in various signalling pathways that lead to cell differentiation, migration, proliferation and maintenance of cellular calcium homeostasis (Gerke et al. 2005, Mussunoor \& Murray 2008, Grewal \& Enrich 2009,
Grewal et al. 2010). Additionally, ANXA1 had higher expression in bovine in vivo-produced 16 cell embryos compared with in vitro-produced 16-cell embryos (Gad et al. 2012). Collectively, greater expression of genes involved in blastocyst development (CLDN4 and SLC9A3), trophectoderm integrity (KRT19), and cell proliferation, growth and anti-apoptosis (LGALS3 and $A N X A 1)$ in embryos collected from FLX-fed cows compared with those fed SUN likely enhanced and supported the development of embryos that otherwise may have undergone degeneration.

Compared with those from cows fed with SUN, embryos from FLX-fed cows exhibited higher expression of the T-box 3 (TBX3, 2.4-fold) and Nanog homeobox

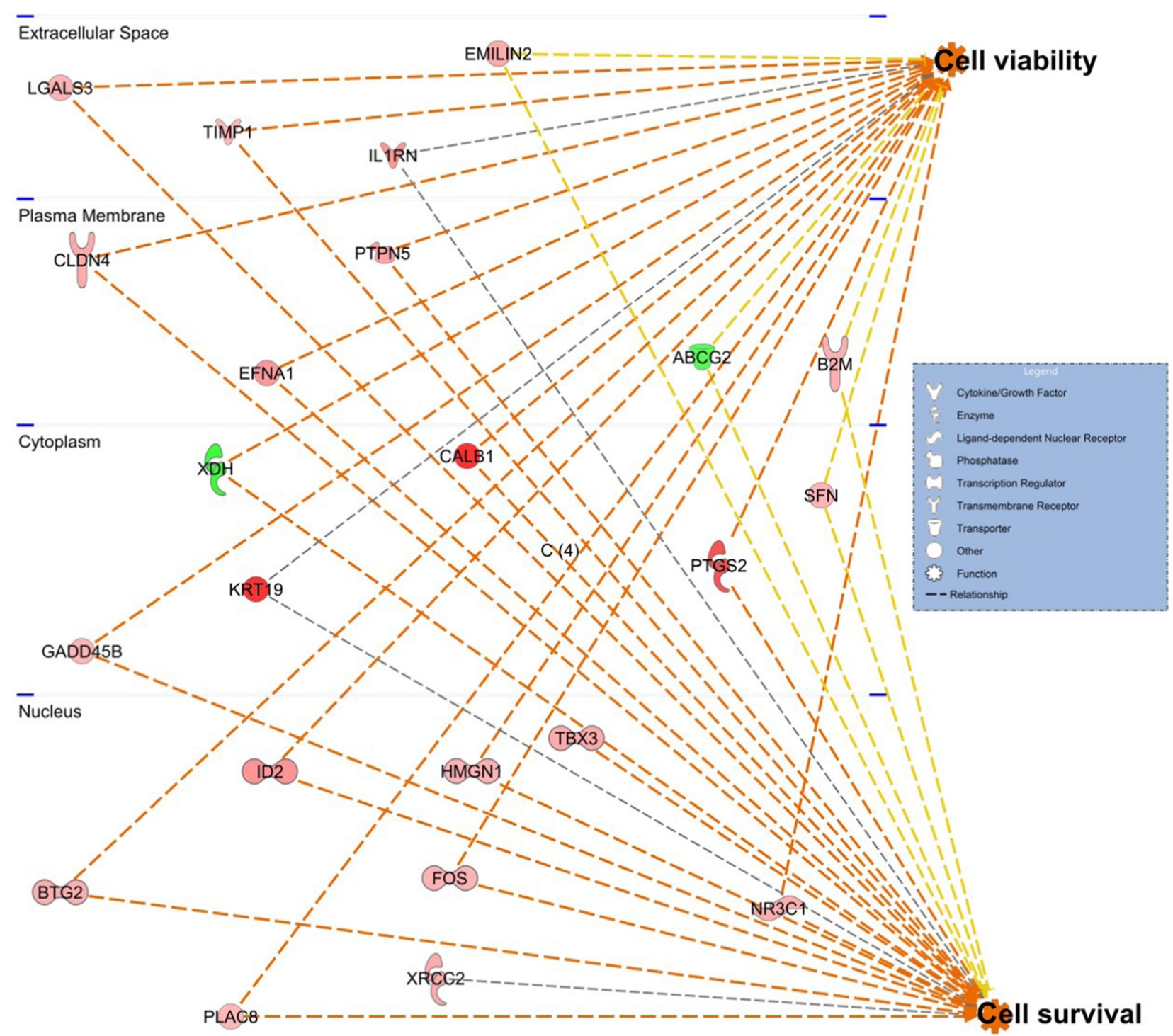

2000-2016 QIAGEN. All rights reserved.

Figure 2 Biological function analysis using Ingenuity Pathway Analysis software. Genes involved in cell viability and survival (Z-score $>2.0)$ functions that are differentially expressed in embryos (day 7.5) collected from cows fed a diet supplemented with flaxseed (FLX) compared with those collected from cows fed sunflower seed (SUN). Up- or downregulated genes involved in these functions are indicated with red and green color symbols respectively. The 175 differentially expressed genes were used for further functional analysis with ingenuity pathway analysis. 
(NANOG, 12.4-fold) genes, which are responsible for early embryonic cell differentiation and lineage segregation. The lack of proper cell differentiation during blastocyst development would result in embryonic death. Several transcription factors have been found being responsible for proper embryonic cell differentiation; for instance, CDX2 is considered as trophectoderm-specific marker at the blastocyst stage (Dietrich \& Hiiragi 2007), whereas the pluripotency marker NANOG is specifically expressed in inner cell mass in bovine embryos (Kuijk et al. 2008). Nanog-null mouse embryos fail to establish epiblast identity because of inner cell mass degeneration (Mitsui et al. 2003, Silva et al. 2009). Additionally, Tbx3, a pluripotency-related transcription factor of the T-box gene family, is necessary for both self-renewal of mouse embryonic stem cells and for their differentiation into embryonic endoderm (Chapman et al. 1996). Among T-box family members, Tbx3 is the earliest expressed gene in mouse inner cell mass cells (Chapman et al. 1996), and its deletion results in embryonic lethality or deficiencies in the mammary gland, limbs and yolk sac (Davenport et al. 2003). Therefore, it is suggested that the reduction in the proportion of degenerated embryos reported in cows fed a diet enriched in FLX is the result of a higher embryonic expression of $T B X 3$ and NANOG genes.

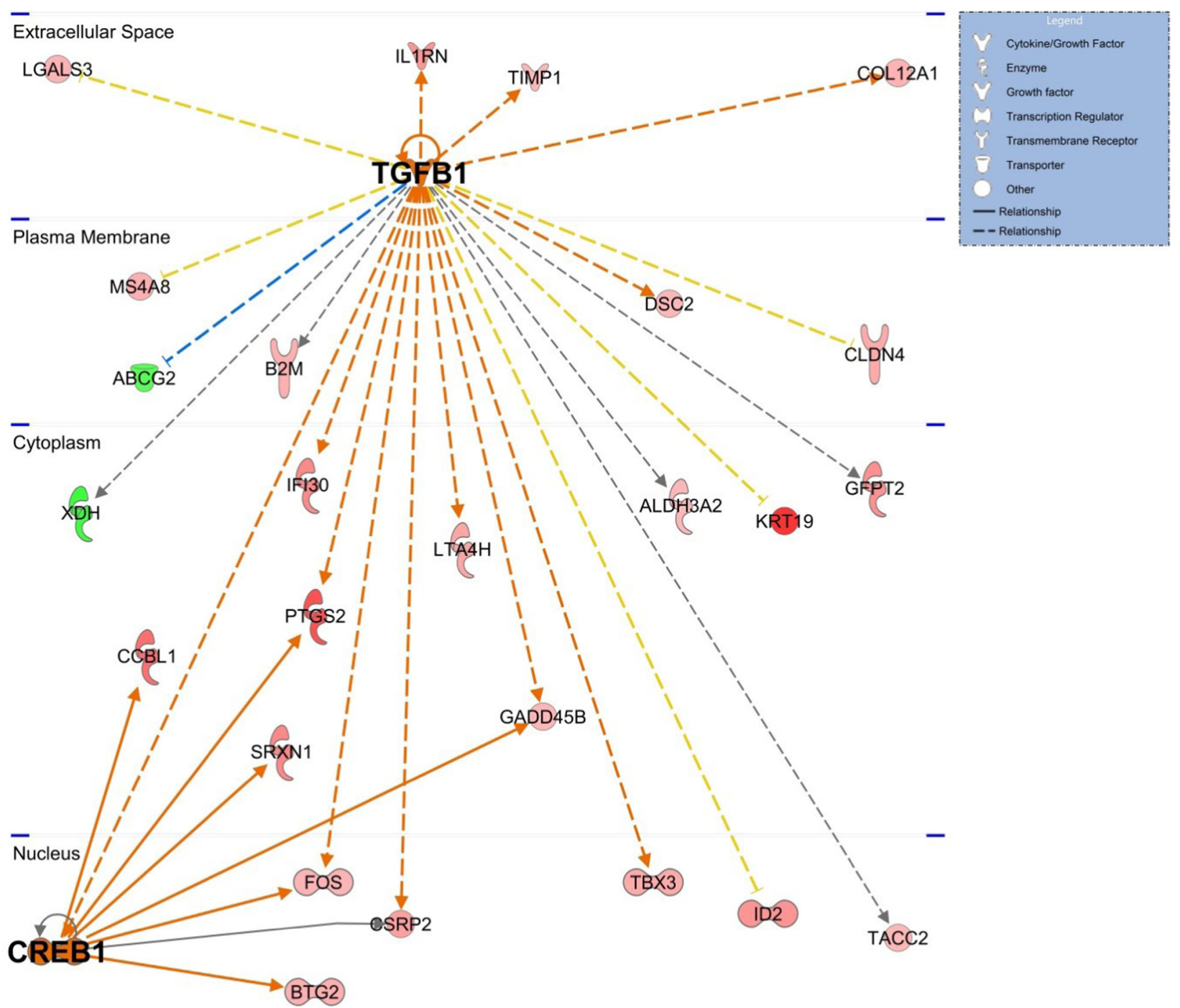

O 2000-2016 QIAGEN. All rights reserved.

Figure 3 Upstream regulator of differentially expressed genes in embryos (Day 7.5) collected from cows fed a diet supplemented with flaxseed (FLX) compared with those collected from cows fed sunflower seed (SUN). cAMP-responsive element binding protein 1 (CREB1; transcription factor) and transforming growth factor beta 1 (TGF- $\beta 1$; growth factors) are the upstream regulators of differentially expressed genes in embryos (Day 7.5) collected from cows fed a diet supplemented with flaxseed (FLX) compared with those collected from cows fed a diet supplemented with sunflower seed (SUN). Up- or downregulated genes are indicated with red and green colour symbols respectively. Direct or indirect relationships between molecules are indicated by solid or dashed connecting lines respectively. The analysis of upstream regulator of differentially expressed genes was done with Ingenuity Pathway Analysis software. 
Feeding a diet enriched in FLX increased the blastocyst expression of transmembrane receptor beta-2-microglobulin (B2M, 2.3-fold) and placentaspecific 8 (PLAC8, 2.0-fold) involved in cell survival. Recent studies have shown that B2M expression increased in embryos at blastocyst stage (Tanaka et al. 2005) and in endometrial tissue around the time of maternal recognition of pregnancy (Forde et al. 2011). The increased expression of $B 2 \mathrm{~m}$ gene is positively correlated with the expression of blastocyst MHC class la, which protects embryonic trophoblast cells from maternal NK cells (Tanaka et al. 2005), thus avoiding maternal rejection of the embryo (Lanier 1998). Interestingly, it has been found that $B 2 \mathrm{~m}$ expression was downregulated in in vivo-derived bovine embryos that resulted in no pregnancy or greater pregnancy loss relative to those embryos that resulted in pregnancies carried to term (Ghanem et al. 2011). Similarly, the expression of PLAC8 gene was upregulated (26-fold) in blastocyst biopsies obtained from embryos that resulted in full-term calves compared with those associated with pregnancy loss (El-Sayed et al. 2006), as well as in the endometrium of pregnant cows compared with non-pregnant ones (Galvez et al. 2003, Klein et al. 2006), suggesting a possible role of PLAC8 in placenta development and fetus-maternal interface. Hence, the increased expression of genes involved in maternal immunity modulation (B2M) and placenta development (PLAC8) in blastocysts collected from cows fed FLX compared with those obtained from cows fed SUN supports previous findings regarding reduced pregnancy loss in lactating cows fed a diet supplemented with flaxseed (Ambrose et al. 2006, Petit \& Twagiramungu 2006).

The IPA upstream regulator analysis predicts that cAMP-responsive element binding protein 1 (CREB1) and transforming growth factor beta 1 (TGF- $\beta 1$ ) are the upstream regulators of activated (or inhibited) genes by FLX vs SUN (Fig. 3). The CREB family consists of a family of transcription factors that support somatic cell survival, and this has been most fully investigated in neuronal signalling (Walton \& Dragunow 2000). FBJ murine osteosarcoma viral oncogene homolog (FOS) and prostaglandin-endoperoxide synthase 2 (PTGS2) are a part of CREB 1 and TGF- $\beta 1$ target genes respectively. In this study, FOS and PTGS2 mRNA expression was greater by 2.2- and 5.0-fold in blastocysts collected from cows fed FLX compared with SUN. FOS mainly regulates cell proliferation, differentiation and survival (Hess et al. 2004) and is present in pre-implantation embryos of several species such as the cow, sheep, pig and mouse (Muller et al. 1982, Whyte \& Stewart 1989, Pal et al. 1993, Xavier et al. 1997, Tetens et al. 2000). In knockout experiments, Fos-deficient mice died just before birth, indicating the importance of FOS in foetal survival (Johnson et al. 1992). It has been suggested that in sheep and cows, conceptus-secreted prostaglandins modulate endometrial gene expression, which subsequently leads to enhanced embryo elongation and maternal recognition of pregnancy (Dorniak et al. 2012, Spencer et al. 2013). Moreover, greater expression of PTGS2 was detected in biopsies derived from blastocysts resulting in successful pregnancy and calf delivery (El-Sayed et al. 2006). Ptgs2-null mice have multiple reproductive impairments characterized by poor ovulation, reduced fertilization rates and failure of implantation and decidualization, which are responsive to prostaglandin replacement (Dinchuk et al. 1995, Lim et al. 1997).

Our microarray results indicate that sulfiredoxin 1 (SRXN1, 3.4 fold) and interleukin 1 receptor antagonist $(I L 1 R N, 3.0$ fold) are more expressed in blastocysts collected from cows fed FLX than those collected from cows fed SUN. In addition, the IPA upstream regulator analysis predicted that SRXN1 and ILIRN are CREB1 and TGF- $\beta 1$ target genes respectively. Srnx 1 eliminates reactive oxygen species (e.g., $\mathrm{H}_{2} \mathrm{O}_{2}$ and $\mathrm{NO}$ ) and protects cells from apoptosis (Baek et al. 2012). Three members of the interleukin-1 (IL-1) family, IL-1 $\beta$, IL1RN and IL-1 receptor type I, are present in oocytes and in all stages of human embryo (De los Santos et al. 1996). Exposure of bovine oocytes to a mixture of stearic, palmitic and oleic acid during in vitro maturation reduced the expression of ILIRN in formed blastocysts (Van Hoeck et al. 2015). Interestingly, in our study, ILIRN expression increased in embryos collected from cows fed a diet enriched in FLX. Collectively, these findings indicate that ILIRN expression in bovine embryos is affected by different types of fatty acids. However, further investigations are required to elucidate the exact function of ILIRN genes during the development of bovine embryo.

Based on the microarray analysis, six genes were validated by $\mathrm{q}-\mathrm{PCR}$ in three additional biological replicates (each containing a pool of three to five grade 1 and 2 blastocysts) per dietary treatment (Fig. 4). They


Figure 4 q-PCR confirmation of microarray results in embryos (Day 7.5) collected from cows fed a diet supplemented with flax (FLX) or sunflower (SUN) seed. ${ }^{*} P<0.05 ;^{+} P<0.10$. 
confirmed the upregulation of LGALS3 in FLX compared to SUN embryos. Moreover, there was a tendency for a higher expression of PTGS2, ANXA1 and ILIRN genes in embryos collected from cows fed FLX than those fed SUN. Although greater expression of KRT19 and SRXN1 was apparent, the difference was not significant between FLX and SUN.

Our results indicate that the reduction in embryo degeneration seen in cows fed a diet enriched in $\alpha$-linolenic acid (flaxseed) likely resulted from enhanced embryonic cell proliferation, survival and viability. It is therefore plausible that reduced pregnancy losses previously reported (Ambrose et al. 2006, Petit \& Twagiramungu 2006) in cows fed diets enriched in $n-3$ PUFA occurred through improved embryo survival.

\section{Supplementary data}

This is linked to the online version of the paper at http://dx.doi. org/10.1530/REP-16-0093.

\section{Declaration of interest}

The authors declare that there is no conflict of interest that could be perceived as prejudicing the impartiality of the research reported.

\section{Funding}

This research was jointly supported by Alberta Livestock and Meat Agency, Alberta Innovates - BioSolutions and Alberta Milk (Agriculture Funding Consortium Grant \# 2014R029R), Livestock Research Branch, Alberta Agriculture and Forestry, and the Canadian Institutes of Health Research (MOP-10369).

\section{Acknowledgements}

The authors thank Dr Ana Ruiz-Sanchez for providing technical assistance.

\section{References}

Aardema H, Vos PL, Lolicato F, Roelen BA, Knijn HM, Vaandrager AB, Helms JB \& Gadella BM 2011 Oleic acid prevents detrimental effects of saturated fatty acids on bovine oocyte developmental competence. Biology of Reproduction 85 62-69. (doi:10.1095/ biolreprod.110.088815)

Abedini A, Zamberlam G, Boerboom D \& Price CA 2015 Non-canonical WNT5A is a potential regulator of granulosa cell function in cattle. Molecular and Cellular Endocrinology 403 39-45. (doi:10.1016/j. mce.2015.01.017)

Ambrose DJ, Kastelic JP, Corbett R, Pitney PA, Petit HV, Small JA \& Zalkovic P 2006 Lower pregnancy losses in lactating dairy cows fed a diet enriched in alpha-linolenic acid. Journal of Dairy Science $\mathbf{8 9}$ 3066-3074. (doi:10.3168/jds.S0022-0302(06)72581-4)

Baek JY, Han SH, Sung SH, Lee HE, Kim YM, Noh YH, Bae SH, Rhee SG \& Chang TS 2012 Sulfiredoxin protein is critical for redox balance and survival of cells exposed to low steady-state levels of H2O2. Journal of Biological Chemistry 287 81-89. (doi:10.1074/jbc.M111.316711)
Blazejczyk M, Miron M \& Nadon R 2007 FlexArray: A statistical data analysis software for gene expression microarrays. McGill University and Génome Québec Innovation Centre, Montreal, Canada. http:// gqinnovationcenter.com/.

Burke JM, Staples CR, Risco CA, de la Sota RL \& Thatcher WW 1997 Effect of ruminant grade Menhaden fish meal on reproductive and productive performance of lactating dairy cows. Journal of Dairy Science $\mathbf{8 0}$ 3386-3398. (doi:10.3168/jds.S0022-0302(97)76314-8)

Cerri RL, Juchem SO, Chebel RC, Rutigliano HM, Bruno RG, Galvao KN, Thatcher WW \& Santos JE 2009 Effect of fat source differing in fatty acid profile on metabolic parameters, fertilization, and embryo quality in high-producing dairy cows. Journal of Dairy Science 92 1520-1531. (doi:10.3168/jds.2008-1614)

Chapman DL, Garvey N, Hancock S, Alexiou M, Agulnik SI, GibsonBrown JJ, Cebra-Thomas J, Bollag RJ, Silver LM \& Papaioannou VE 1996 Expression of the T-box family genes, Tbx1-Tbx5, during early mouse development. Developmental Dynamics 206 379-390. (doi:10.1002/ (SICl)1097-0177(199608)206:4<379::AID-AJA4>3.0.CO;2-F)

Childs S, Carter F, Lynch CO, Sreenan JM, Lonergan P, Hennessy AA \& Kenny DA 2008 Embryo yield and quality following dietary supplementation of beef heifers with $n-3$ polyunsaturated fatty acids (PUFA). Theriogenology 70 992-1003. (doi:10.1016/j. theriogenology.2008.06.008)

Colazo MG, Martinez MF, Small JA, Kastelic JP, Burnley CA, Ward DR \& Mapletoft RJ 2005 Effect of estradiol valerate on ovarian follicle dynamics and superovulatory response in progestin-treated cattle. Theriogenology 63 1454-1468. (doi:10.1016/j.theriogenology.2004.07.004)

Cruz-Hernandez C, Kramer JK, Kennelly JJ, Glimm DR, Sorensen BM, Okine EK, Goonewardene LA \& Weselake RJ 2007 Evaluating the conjugated linoleic acid and trans 18:1 isomers in milk fat of dairy cows fed increasing amounts of sunflower oil and a constant level of fish oil. Journal of Dairy Science 90 3786-3801. (doi:10.3168/jds.2006-698)

Davenport TG, Jerome-Majewska LA \& Papaioannou VE 2003 Mammary gland, limb and yolk sac defects in mice lacking Tbx3, the gene mutated in human ulnar mammary syndrome. Development 130 2263-2273. (doi:10.1242/dev.00431)

De los Santos MJ, Mercader A, Frances A, Portoles E, Remohi J, Pellicer A \& Simon C 1996 Role of endometrial factors in regulating secretion of components of the immunoreactive human embryonic interleukin-1 system during embryonic development. Biology of Reproduction $\mathbf{5 4}$ 563-574. (doi:10.1095/biolreprod54.3.563)

Demant M 2012 Qualitative and quantitative proteome analyses of bovine oocytes and early embryos. In Laboratory for Functional Genome Analysis, pp 119. Gene Center, Ludwig Maximilian University of Munich: Munich, Germany.

Dietrich JE \& Hiiragi T 2007 Stochastic patterning in the mouse preimplantation embryo. Development 134 4219-4231. (doi:10.1242/ dev.003798)

Dinchuk JE, Car BD, Focht RJ, Johnston JJ, Jaffee BD, Covington MB, Contel NR, Eng VM, Collins RJ, Czerniak PM et al. 1995 Renal abnormalities and an altered inflammatory response in mice lacking cyclooxygenase II. Nature 378 406-409. (doi:10.1038/378406a0)

Dorniak P, Bazer FW, Wu G \& Spencer TE 2012 Conceptus-derived prostaglandins regulate endometrial function in sheep. Biology of Reproduction 87 9. (doi:10.1095/biolreprod.112.100487)

El-Sayed A, Hoelker M, Rings F, Salilew D, Jennen D, Tholen E, Sirard MA, Schellander K \& Tesfaye D 2006 Large-scale transcriptional analysis of bovine embryo biopsies in relation to pregnancy success after transfer to recipients. Physiological Genomics 28 84-96. (doi:10.1152/ physiolgenomics.00111.2006)

Ferguson EM \& Leese HJ 2006 A potential role for triglyceride as an energy source during bovine oocyte maturation and early embryo development. Molecular Reproduction and Development 73 1195-1201. (doi:10.1002/mrd.20494)

Folch J, Lees M \& Sloane Stanley GH 1957 A simple method for the isolation and purification of total lipids from animal tissues. Journal of Biological Chemistry 226 497-509.

Forde N, Carter F, Spencer TE, Bazer FW, Sandra O, Mansouri-Attia N, Okumu LA, McGettigan PA, Mehta JP, McBride R et al. 2011 Conceptusinduced changes in the endometrial transcriptome: how soon does the cow know she is pregnant? Biology of Reproduction 85 144-156. (doi:10.1095/biolreprod.110.090019) 
Friedrichs J, Torkko JM, Helenius J, Teravainen TP, Fullekrug J, Muller DJ, Simons K \& Manninen A 2007 Contributions of galectin-3 and -9 to epithelial cell adhesion analyzed by single cell force spectroscopy. Journal of Biological Chemistry 282 29375-29383. (doi:10.1074/jbc. M701867200)

Gad A, Hoelker M, Besenfelder U, Havlicek V, Cinar U, Rings F, Held E, Dufort I, Sirard MA, Schellander K et al. 2012 Molecular mechanisms and pathways involved in bovine embryonic genome activation and their regulation by alternative in vivo and in vitro culture conditions. Biology of Reproduction 87 100. (doi:10.1095/biolreprod.112.099697)

Galvez AS, Ulloa JA, Chiong M, Criollo A, Eisner V, Barros LF \& Lavandero S 2003 Aldose reductase induced by hyperosmotic stress mediates cardiomyocyte apoptosis: differential effects of sorbitol and mannitol. Journal of Biological Chemistry 278 38484-38494. (doi:10.1074/jbc. M211824200)

Gerke V, Creutz CE \& Moss SE 2005 Annexins: linking Ca2+ signalling to membrane dynamics. Nature Reviews Molecular Cell Biology 6 449-461. (doi:10.1038/nrm1661)

Ghanem N, Salilew-Wondim D, Gad A, Tesfaye D, Phatsara C, Tholen E, Looft C, Schellander K \& Hoelker M 2011 Bovine blastocysts with developmental competence to term share similar expression of developmentally important genes although derived from different culture environments. Reproduction 142 551-564. (doi:10.1530/ REP-10-0476)

Grewal T \& Enrich C 2009 Annexins - modulators of EGF receptor signalling and trafficking. Cell Signalling 21 847-858. (doi:10.1016/j. cellsig.2009.01.031)

Grewal T, Koese M, Rentero C \& Enrich C 2010 Annexin A6-regulator of the EGFR/Ras signalling pathway and cholesterol homeostasis. International Journal of Biochemistry \& Cell Biology 42 580-584. (doi:10.1016/j. biocel.2009.12.020)

Hess J, Angel P \& Schorpp-Kistner M 2004 AP-1 subunits: quarrel and harmony among siblings. Journal of Cell Science 117 5965-5973. (doi:10.1242/jcs.01589)

Hesse M, Franz T, Tamai Y, Taketo MM \& Magin TM 2000 Targeted deletion of keratins 18 and 19 leads to trophoblast fragility and early embryonic lethality. EMBO Journal 19 5060-5070. (doi:10.1093/emboj/19.19.5060)

Hunter RH 1989 Ageing of the unfertilized cow egg in vivo: how soon is fertility compromised? Veterinary Record 124 489-490. (doi:10.1136/ vr.124.18.489)

Johnson RS, Spiegelman BM \& Papaioannou V 1992 Pleiotropic effects of a null mutation in the c-fos proto-oncogene. Cell 71 577-586. (doi:10.1016/0092-8674(92)90592-Z)

Kawagishi R, Tahara M, Sawada K, Morishige K, Sakata M, Tasaka K \& Murata $\mathbf{Y} 2004 \mathrm{Na}+/ \mathrm{H}+$ exchanger-3 is involved in mouse blastocyst formation. Journal of Experimental Zoology Part A: Comparative Experimental Biology 301 767-775. (doi:10.1002/jez.a.90)

Khalil WA, Marei WF \& Khalid M 2013 Protective effects of antioxidants on linoleic acid-treated bovine oocytes during maturation and subsequent embryo development. Theriogenology 80 161-168. (doi:10.1016/j. theriogenology.2013.04.008)

Klein C, Bauersachs S, Ulbrich SE, Einspanier R, Meyer HH, Schmidt SE, Reichenbach HD, Vermehren M, Sinowatz F, Blum H et al. 2006 Monozygotic twin model reveals novel embryo-induced transcriptome changes of bovine endometrium in the preattachment period. Biology of Reproduction 74 253-264. (doi:10.1095/biolreprod.105.046748)

Kuijk EW, Du Puy L, Van Tol HT, Oei CH, Haagsman HP, Colenbrander B \& Roelen BA 2008 Differences in early lineage segregation between mammals. Developmental Dynamics 237 918-927. (doi:10.1002/ dvdy.21480)

Lanier LL 1998 NK cell receptors. Annual Review of Immunology 16 359-393. (doi:10.1146/annurev.immunol.16.1.359)

Leroy JL, Vanholder T, Delanghe JR, Opsomer G, Van Soom A, Bols PE, Dewulf J \& de Kruif A 2004 Metabolic changes in follicular fluid of the dominant follicle in high-yielding dairy cows early post partum. Theriogenology 62 1131-1143. (doi:10.1016/j. theriogenology.2003.12.017)

Leroy JL, Vanholder T, Mateusen B, Christophe A, Opsomer G, de Kruif A, Genicot G \& Van Soom A 2005 Non-esterified fatty acids in follicular fluid of dairy cows and their effect on developmental capacity of bovine oocytes in vitro. Reproduction 130 485-495. (doi:10.1530/ rep.1.00735)
Lim H, Paria BC, Das SK, Dinchuk JE, Langenbach R, Trzaskos JM \& Dey SK 1997 Multiple female reproductive failures in cyclooxygenase 2-deficient mice. Cell 91 197-208. (doi:10.1016/S0092-8674(00)80402-X)

Liu FT, Patterson RJ \& Wang JL 2002 Intracellular functions of galectins. Biochimica et Biophysica Acta 1572 263-273. (doi:10.1016/S03044165(02)00313-6)

Marei WF, Wathes DC \& Fouladi-Nashta AA 2009 The effect of linolenic Acid on bovine oocyte maturation and development. Biology of Reproduction 81 1064-1072. (doi:10.1095/biolreprod.109.076851)

Marei WF, Wathes DC \& Fouladi-Nashta AA 2010 Impact of linoleic acid on bovine oocyte maturation and embryo development. Reproduction 139 979-988. (doi:10.1530/REP-09-0503)

Mattos R, Staples CR \& Thatcher WW 2000 Effects of dietary fatty acids on reproduction in ruminants. Reviews of Reproduction 5 38-45. (doi:10.1530/ror.0.0050038)

McEvoy TG, Coull GD, Broadbent PJ, Hutchinson JS \& Speake BK 2000 Fatty acid composition of lipids in immature cattle, pig and sheep oocytes with intact zona pellucida. Journal of Reproduction and Fertility 118 163-170. (doi:10.1530/jrf.0.1180163)

Mitsui K, Tokuzawa Y, Itoh H, Segawa K, Murakami M, Takahashi K, Maruyama M, Maeda M \& Yamanaka S 2003 The homeoprotein Nanog is required for maintenance of pluripotency in mouse epiblast and ES cells. Cell 113 631-642. (doi:10.1016/S0092-8674(03)00393-3)

Moallem U, Shafran A, Zachut M, Dekel I, Portnick Y \& Arieli A 2013 Dietary alpha-linolenic acid from flaxseed oil improved folliculogenesis and IVF performance in dairy cows, similar to eicosapentaenoic and docosahexaenoic acids from fish oil. Reproduction 146 603-614. (doi:10.1530/REP-13-0244)

Moriwaki K, Tsukita S \& Furuse M 2007 Tight junctions containing claudin 4 and 6 are essential for blastocyst formation in preimplantation mouse embryos. Developmental Biology 312 509-522. (doi:10.1016/j. ydbio.2007.09.049)

Muller R, Slamon DJ, Tremblay JM, Cline MJ \& Verma IM 1982 Differential expression of cellular oncogenes during pre- and postnatal development of the mouse. Nature 299 640-644. (doi:10.1038/299640a0)

Mussunoor S \& Murray Gl 2008 The role of annexins in tumour development and progression. Journal of Pathology 216 131-140. (doi:10.1002/path.2400)

Nangia-Makker P, Nakahara S, Hogan V \& Raz A 2007 Galectin-3 in apoptosis, a novel therapeutic target. Journal of Bioenergetics and Biomembranes 39 79-84. (doi:10.1007/s10863-006-9063-9)

Paczkowski M, Silva E, Schoolcraft WB \& Krisher RL 2013 Comparative importance of fatty acid beta-oxidation to nuclear maturation, gene expression, and glucose metabolism in mouse, bovine, and porcine cumulus oocyte complexes. Biology of Reproduction $\mathbf{8 8} 111$. (doi:10.1095/biolreprod.113.108548)

Paczkowski M, Schoolcraft WB \& Krisher RL 2014 Fatty acid metabolism during maturation affects glucose uptake and is essential to oocyte competence. Reproduction 148 429-439. (doi:10.1530/ REP-14-0015)

Pal SK, Crowell R, Kiessling AA \& Cooper GM 1993 Expression of proto-oncogenes in mouse eggs and preimplantation embryos. Molecular Reproduction and Development 35 8-15. (doi:10.1002/ mrd.1080350103)

Petit HV \& Twagiramungu H 2006 Conception rate and reproductive function of dairy cows fed different fat sources. Theriogenology $\mathbf{6 6}$ 1316-1324. (doi:10.1016/j.theriogenology.2006.04.029)

Pfaffl MW 2001 A new mathematical model for relative quantification in real-time RT-PCR. Nucleic Acids Research 29 e45. (doi:10.1093/ nar/29.9.e45)

Robert C, Nieminen J, Dufort I, Gagne D, Grant JR, Cagnone G, Plourde D, Nivet AL, Fournier E, Paquet E et al. 2011 Combining resources to obtain a comprehensive survey of the bovine embryo transcriptome through deep sequencing and microarrays. Molecular Reproduction and Development 78 651-664. (doi:10.1002/mrd.21364)

Robinson RS, Fray MD, Wathes DC, Lamming GE \& Mann GE 2006 In vivo expression of interferon tau mRNA by the embryonic trophoblast and uterine concentrations of interferon tau protein during early pregnancy in the cow. Molecular Reproduction and Development 73 470-474. (doi:10.1002/mrd.20431)

Silva J, Nichols J, Theunissen TW, Guo G, van Oosten AL, Barrandon O, Wray J, Yamanaka S, Chambers I \& Smith A 2009 Nanog is the gateway 
to the pluripotent ground state. Cell 138 722-737. (doi:10.1016/j. cell.2009.07.039)

Smyth GK 2005 Limma: Linear Models for Microarray Data. New York, NY, USA: Springer.

Spencer TE, Forde N, Dorniak P, Hansen TR, Romero JJ \& Lonergan P 2013 Conceptus-derived prostaglandins regulate gene expression in the endometrium prior to pregnancy recognition in ruminants. Reproduction 146 377-387. (doi:10.1530/REP-13-0165)

Tanaka T, Ebata T, Tajima A, Kinoshita K, Okumura K \& Yagita H 2005 Beta2-microglobulin required for cell surface expression of blastocyst MHC. Biochemical and Biophysical Research Communications 332 311-317. (doi:10.1016/j.bbrc.2005.03.249)

Tetens F, Kliem A, Tscheudschilsuren G, Navarrete Santos A \& Fischer B 2000 Expression of proto-oncogenes in bovine preimplantation blastocysts. Anatomy and Embryology 201 349-355. (doi:10.1007/ s004290050324)

Thangavelu G, Colazo MG, Ambrose DJ, Oba M, Okine EK \& Dyck MK 2007 Diets enriched in unsaturated fatty acids enhance early embryonic development in lactating Holstein cows. Theriogenology 68 949-957. (doi:10.1016/j.theriogenology.2007.07.002)

Thatcher WW, Santos JE, Silvestre FT, Kim IH \& Staples CR 2010 Perspective on physiological/endocrine and nutritional factors influencing fertility in post-partum dairy cows. Reproduction in Domestic Animals 45 2-14. (doi:10.1111/j.1439-0531.2010.01664.x)

Tsoi S, Zhou C, Grant JR, Pasternak JA, Dobrinsky J, Rigault P, Nieminen J, Sirard MA, Robert C, Foxcroft GR et al. 2012 Development of a porcine (Sus scofa) embryo-specific microarray: array annotation and validation. BMC Genomics 13 370. (doi:10.1186/1471-2164-13-370)

Van Hoeck V, Rizos D, Gutierrez-Adan A, Pintelon I, Jorssen E, Dufort I, Sirard MA, Verlaet A, Hermans N, Bols PEJ et al. 2015 Interaction between differential gene expression profile and phenotype in bovine blastocysts originating from oocytes exposed to elevated non-esterified fatty acid concentrations. Reproduction, Fertility and Development $\mathbf{2 7}$ 372-384. (doi:10.1071/RD13263)

Vanholder T, Leroy JL, Soom AV, Opsomer G, Maes D, Coryn M \& de Kruif A 2005 Effect of non-esterified fatty acids on bovine granulosa cell steroidogenesis and proliferation in vitro. Animal Reproduction Sciences 87 33-44. (doi:10.1016/j.anireprosci.2004.09.006)

Walton MR \& Dragunow I 2000 Is CREB a key to neuronal survival? Trends in Neurosciences 23 48-53. (doi:10.1016/S01662236(99)01500-3)

Whyte A \& Stewart HJ 1989 Expression of the proto-oncogene fos (c-fos) by preimplantation blastocysts of the pig. Development 105 651-656.

Xavier F, Lagarrigue S, Guillomot M \& Gaillard-Sanchez I 1997 Expression of c-fos and jun protooncogenes in ovine trophoblasts in relation to interferon-tau expression and early implantation process. Molecular Reproduction and Development 46 127-137. (doi:10.1002/(SICl)10982795(199702)46:2<127::AID-MRD3>3.0.CO;2-S)

Yun CH, Tse CM, Nath SK, Levine SA, Brant SR \& Donowitz M 1995 Mammalian $\mathrm{Na}+/ \mathrm{H}+$ exchanger gene family: structure and function studies. American Journal of Physiology 269 G1-G11. (doi:10.1113/ jphysiol.1995.sp020558)

Received 22 February 2016

First decision 8 April 2016

Revised manuscript received 8 September 2016

Accepted 19 September 2016 